\title{
EDUCAÇÃO AMBIENTAL ALIADA AO ENSINO DE QUÍMICA: DESCARTES DE RESÍDUOS ELETRÔNICOS
}

José Francisco Zavaglia Marques ${ }^{1}$; Keiciane Canabarro Drehmer-Marques ${ }^{2}$; Gracieli Dall Ostro Persich ${ }^{3}$

\section{RESUMO}

A abordagem da Educação Ambiental (EA) no ensino busca realizar conexões com os fatores políticos e sociais que podem despertar para reflexão do sujeito sobre suas responsabilidades. Diante dessa necessidade foi realizada uma Sequência Didática sobre lixo eletrônico com os estudantes do $3^{\circ}$ ano do Ensino Médio de um colégio privado de Rosário do Sul-RS. Dentre as etapas realizadas envolveram leitura e discussão de textos, aula expositiva, construção de coletores e panfletos de divulgação e uma palestra com a bióloga do município. As atividades permitiram a participação ativa dos estudantes e sensibilização sobre resíduos eletrônicos expandindo para os demais discentes da escola e comunidade escolar.

Palavras-chave: Resíduos eletrônicos; Sequência Didática; Educação Ambiental.

\section{ENVIRONMENTAL EDUCATION ALLIED TO CHEMISTRY TEACHING: DISCARDS OF ELECTRONIC WASTE}

\begin{abstract}
The approach of Environmental Education (EA) in teaching seeks to make connections with the political and social factors that can awaken to the subject's reflection on their responsibilities. Faced with this need was fulfilled a learning sequence on electronic junk with the students of the 3rd year of high school in a private school in Rosário do Sul, RS. Among the stages involved reading and discussion of texts, lectures, construction of collectors and dissemination pamphlets and a lecture with the biologist of the municipality. The activities allowed the active participation of the students and awareness about electronic waste expanding to the other students of the school and school community.
\end{abstract}

Keywords: Electronic waste.Teaching/learning sequence.Environmental education.

1 Mestre em Nanociências (UFN). Professor da Educação Básica. E-mail: franciscoquimica12@gmail.com.

2 Doutoranda em Educação em Ciências: Química da Vida e Saúde (UFSM). E-mail: keicibio@gmail.com.

3 Mestra em Educação em Ciências: Química da Vida e Saúde (UFSM). E-mail: seducgracieli@gmail.com. 


\section{Educação ambiental e o ensino-aprendizagem}

A crise ambiental tem sido cada vez mais abordada nos meios de comunicações. Isso se deve a uma preocupação crescente devido ao esgotamento dos recursos naturais, aliado com o aumento da quantidade de resíduos sólidos gerados na linha de produção de mercadorias para consumo. O despertar da consciência ambiental por meio do ensino-aprendizagem pode gerar mudanças no comportamento e nas concepções do ser humano em relação à natureza, pela via das reflexões que possam conduzir a uma mudança na ideia de que a natureza está à mercê do homem, para um pensamento de responsabilidade com o ambiente e com o outro (BEGNAME et al., 2015; SILVA; OLIVEIRA; TORRES, 2014).

Devemos ter maior preocupação com as mudanças de atitudes do sujeito do que em relação ao seu comportamento, pois este último poderá apresentar-se de diferentes maneiras em locais distintos. Contudo, as suas atitudes são um conjunto de crenças, valores, éticas e estéticas que orientam o sujeito ecológico e que poderão ser aplicadas em locais diversos em determinada ação, a qual terá uma reação de acordo com seus agregados (CARVALHO, 2004). Na formação escolar, com base nos Parâmetros Curriculares Nacionais (PCN), as reflexões que o sujeito deve desenvolver incluem valores que possibilitam mudanças de conduta e de compromisso com as questões da vida local e global (BRASIL, 2000).

Pensando nesse sentido, a Educação Ambiental (EA) deve ser abordada nas escolas como um tema transversal, mas muitas vezes os docentes a negligenciam devido aos seus compromissos com o conteúdo que deve ser cumprido até o fim do ano letivo (BRASIL, 1999; CUBA, 2010). Entretanto, ressaltamos que é possível trabalhar EA e o conteúdo curricular sem separações ou ambiguidades, pois ser transversal é realizar inter-relações entre as questões ligadas ao ambiente e aos fatores políticos, econômicos, históricos e sociais (TRAVASSOS, 2004).

As recomendações do Programa Nacional de Educação Ambiental (PRONEA) buscam a proteção, recuperação e melhoria na qualidade de vida do sujeito e para isso o documento orienta que o currículo deve conter a temática ambiental de maneira transversal em todas as áreas do 
conhecimento, de forma contínua e permanente no ensino de caráter formal e não-formal (BRASIL, 2014).

Já a Lei de Diretrizes Básicas (LDB) tem como um dos seus objetivos a formação dos educandos atrelada à promoção da responsabilidade, da ética e do exercício da cidadania. Tanto na forma individual quanto no coletivo, enfrentando os problemas e as soluções relacionadas à ciência e a tecnologia, essas ideias foram tratadas na conferência das Nações Unidas sobre o meio ambiente e retomadas no Rio de Janeiro em 1992, em um evento conhecido como ECO-92 (ABREU, 2008; BRASIL, 1996).

A abordagem da EA nas escolas é uma forma de contextualizar o ensino na formação do cidadão crítico, capaz de transformar o meio em que vive com intenção de melhorar a sua qualidade de vida e a preservação do meio ambiente (WUILLDA et al., 2017). Ao buscar uma formação de pessoas comprometidas com as questões ambientais, sensibilizadas para preservar 0 meio ambiente e buscar mudanças de hábitos, fazendo disso uma simples mudança de atitude. Como sugerido por Zorzan e Bertan (2017), um exemplo de ação que pode ser desenvolvida em âmbito escolar é o recolhimento de pilhas e baterias que não estão em uso e destinar para a coleta adequada. Tais resíduos são classificados como lixo eletrônico, assunto aprofundado a seguir.

\section{Lixo eletrônico}

O termo "lixo eletrônico" e a necessidade da destinação final adequada para esse tipo de resíduo surgiu como resultado do crescente consumo de equipamentos eletrônicos, intensificado pelo avanço da tecnologia e a diminuição da vida útil dos aparelhos celulares, televisões entre outros eletrônicos. O Brasil, só no ano de 2016, gerou 1,5 milhão de toneladas perdendo no continente americano apenas para os Estados Unidos da América com seus 6,3 milhões no mesmo período (BARBOSA, 2018).

O avanço na tecnologia possibilita melhor qualidade de vida proporcionado agilidade em empresas, escolas e indústrias, pois potencializa a economia. No entanto, agregado a essa facilitação, as tecnologias e, principalmente, os resíduos de seu descarte e produção, causam danos irreparáveis ao meio ambiente. A obsolescência programada permite que os eletrônicos produzidos tenham tempo útil pré-determinado, após esse período, 
os aparelhos tornam-se obsoletos em relação ao funcionamento, à comodidade no seu uso, à duração da bateria, ao software que o alimenta, o que acaba por se tornar um convite à aquisição de um novo produto, desenvolvendo assim uma sociedade do consumismo que acaba produzindo maior quantidade de lixos eletrônicos sem descarte adequado. É necessário refletir sobre as atitudes da sociedade atual, pois ao mesmo tempo que consumimos novos produtos, novos recursos naturais estão sendo extraídas e novos danos ao ambiente estão sendo realizados, principalmente no âmbito da poluição dos solos e das águas pela deposição de materiais tóxicos e outras matérias usadas para a produção de aparelhos eletrônicos (ZORZAN \& BERTAN, 2017).

O artigo 33 da Política Nacional de Resíduos Sólidos (PNRS) descreve como responsabilidade compartilhada a implementação e a estruturação da logística reversa aos fabricantes, importadores, distribuidores e comerciantes dos produtos, na qual ocorre o retorno do produto após o uso do consumidor. Nesse sentido, destacamos o inciso II, sobre pilhas e baterias, e o inciso VI, sobre produtos eletrônicos e seus componentes, que definem sobre as empresas terem a responsabilidade em dar o destino ambiental adequado aos produtos e suas embalagens (BRASIL, 2010).

Os riscos de contaminação ambiental que esses produtos eletrônicos oferecem estão ligados a presença dos metais pesados como o arsênio, cromo, mercúrio, cádmio e o chumbo que podem causar problemas de saúde e danos ambientais no solo e na água, pois são bioacumulados na cadeia alimentar. A bioacumulação ou aumento progressivo da concentração do elemento químico, à medida que avança na cadeia alimentar, vai diminuindo a probabilidade dessas substâncias serem metabolizadas no organismo, sendo lipossolúveis nos tecidos gordurosos dos seres vivos, por isso acumulam-se em seus organismos (BAIRD \& CANN, 2011).

Quando os metais pesados são despejados em cursos de água de forma ilegal não respeitando os limites para o descarte em efluentes, por indústrias, mineradoras, curtumes acarreta riscos à saúde humana e ao meio ambiente. Com intenção de controlar os riscos a legislação brasileira estabelece limites para o descarte de efluentes e do consumo humano da água potável (LIMA \& MERÇON, 2011). 


\section{O ensino de química}

O ensino de química segundo Wuillda et al. (2017), deve promover não só o conhecimento dos conceitos químicos, mas também buscar a compreensão dos temas relevantes para a sociedade e o meio ambiente oportunizando a formação da cidadania. Sendo assim, a contextualização do ensino de ciências incentiva a participação dos estudantes perante a sociedade em que vivem (PEREIRA et al., 2012).

O artigo representa uma proposta de ação no espaço escolar durante 0 ano letivo que busca beneficiar a qualidade da comunidade escolar e promova a cidadania incentivando a mudanças de valores e atitudes como o descarte incorreto do lixo eletrônico no lixo comum. A partir dos estudos conceituais de polímeros e metais buscou-se contextualizar o assunto com as questões da produção do lixo eletrônico. A turma do $3^{\circ}$ ano do Ensino Médio foi desafiada a promoverem ações no espaço escolar.

A partir desta proposta de atividade, o ensino de química permitiu sensibilizar a turma sobre suas atitudes e através do desafio proposto expandiu-se para comunidade escolar trabalhando a importância da reciclagem correta dos resíduos eletrônicos e reforçando a corresponsabilidade no exercício da cidadania frente a sua cidade e assim é esperado um desenvolvimento dos sujeitos mais participativos nos problemas locais e globais.

\section{Percursos metodológicos}

O projeto teve como objetivo abordar a temática de resíduos eletrônicos aliado ao Ensino de Química em busca de uma maior contextualização e na tentativa do desenvolvimento estudantil acerca de uma sensibilização ambiental e corresponsabilidade com meio ambiente. O projeto foi realizado em um colégio privado localizado no município de Rosário do Sul/RS, com a participação de uma turma de $3^{\circ}$ ano do Ensino Médio do sob orientação de um dos autores na posição de professor do componente curricular de Química ao longo de um bimestre do ano letivo. Participaram do projeto 16 estudantes com idades entre 16 a 18 anos. 
Para aplicação do projeto realizado foi utilizada a metodologia de Sequência Didática (SD) de acordo com Zabala (1998) essa tem como intenção a organização de atividades ordenadas e articuladas para realização dos objetivos educacionais. A SD é composta por várias atividades realizadas pelos educandos considerando parte das atitudes, dos procedimentos e execução, sempre com o olhar e mediação do docente. As atividades que compõem a SD parte de um determinado tema e suas execuções permitem um aprofundamento sobre esse.

Para o desenvolvimento da SD utilizamos um bimestre letivo com atividades desenvolvidas em aula e outras fora do horário em que os estudantes deveriam pesquisar e planejar o desenvolvimento de atividades. Diferentes recursos e estratégias didáticas foram utilizadas para implementação da SD visando um desenvolvimento amplo dos educandos dentre elas: leitura e discussão de texto, aula expositiva, atividade prática, produção de material informativo e participação em uma palestra (Quadro 1).

As atividades propostas estão ao alcance dos estudantes e trazem sentido e interesse em sua realização, pois os estudantes se envolvem como protagonista desde seu planejamento, implantação e avaliação. Conforme o autor os desafios devem ser alcançáveis, para que os estudantes sintam que com enfrentamento e esforço poderão superá-los. Os resultados obtidos ao longo da SD serão analisados e discutidos em uma abordagem qualitativa. $O$ quadro 1 representa o planejamento das etapas e suas respectivas descrições das atividades, assim como o tempo para execução das mesmas considerando o tempo do período de 45 minutos.

Quadro 1. Descrição da Sequência Didática realizada com os estudantes

\begin{tabular}{|c|l|c|}
\hline Atividade & \multicolumn{1}{|c|}{ Descrição das etapas } & Tempo \\
\hline $1^{\circ}$-Leitura de texto & $\begin{array}{l}\text { Leitura do texto do livro Química e Sociedade de Santos e } \\
\text { Mól (2013) título: Os plásticos e o ambiente. }\end{array}$ & 1 período \\
\hline $\begin{array}{c}2^{\circ} \text {-Problematização } \\
\text { e discussão }\end{array}$ & $\begin{array}{l}\text { Problematização acerca do consumismo e geração de } \\
\text { resíduos na busca por uma sensibilização dos } \\
\text { estudantes, assim como discussão sobre os tipos de } \\
\text { resíduos produzidos no colégio e as possíveis soluções } \\
\text { para o espaço escolar. }\end{array}$ & 1 período \\
\hline $3^{\circ}$ - Aula expositiva & Aula expositiva sobre materiais Poliméricos e metálicos. & 4 períodos \\
\hline $\begin{array}{c}4^{\circ} \text { - Produção de } \\
\text { coletores }\end{array}$ & $\begin{array}{l}\text { Atividade prática em turma foi dividida em dois grupos } \\
\text { para realizar a produção de coletores com placa de } \\
\text { identificação para ficar em frente ao hall de entrada da } \\
\text { escola. }\end{array}$ & $\begin{array}{c}1 \text { período* } \\
3 \text { semanas }\end{array}$ \\
\hline $5^{\circ}$ - Produção de & No laboratório de informática a turma iniciou a pesquisa e & 2 períodos* \\
\hline
\end{tabular}




\begin{tabular}{|c|l|c|}
\hline panfletos & $\begin{array}{l}\text { elaboração de panfletos para divulgação da campanha de } \\
\text { recolhimento para os estudantes do Ensino Fundamental } \\
\text { Anos Finais. }\end{array}$ & 2 semanas \\
\hline $6^{\circ}$ - Palestra & $\begin{array}{l}\text { Palestra ministrada pela bióloga do município de Rosário } \\
\text { do Sul sobre resíduos sólidos na visão nacional, estadual } \\
\text { e municipal, com a participação de todos o Ensino Médio. }\end{array}$ & 1 período \\
\hline
\end{tabular}

Fonte: Próprio autor.

*Lançamento da proposta, organização dos grupos e explicação da proposta em aula

\section{Resultados e discussões}

No primeiro momento, o professor da turma realizou uma leitura sobre o texto "Os plásticos e o ambiente" (figura 1) pertencente a um livro didático dentro da sessão tema em foco antecedendo o conteúdo de polímeros que iria ser abordando com a turma, após a leitura foi realizado um momento de diálogo com os estudantes. Na segunda etapa foi problematizado com os estudantes uma discussão acerca do consumismo e geração de resíduos, a discussão encaminhou-se para os resíduos gerados no próprio colégio. A terceira etapa da SD ocorreu o momento da aula expositiva sobre polímeros.

Figura 1. Texto trabalhado em aula

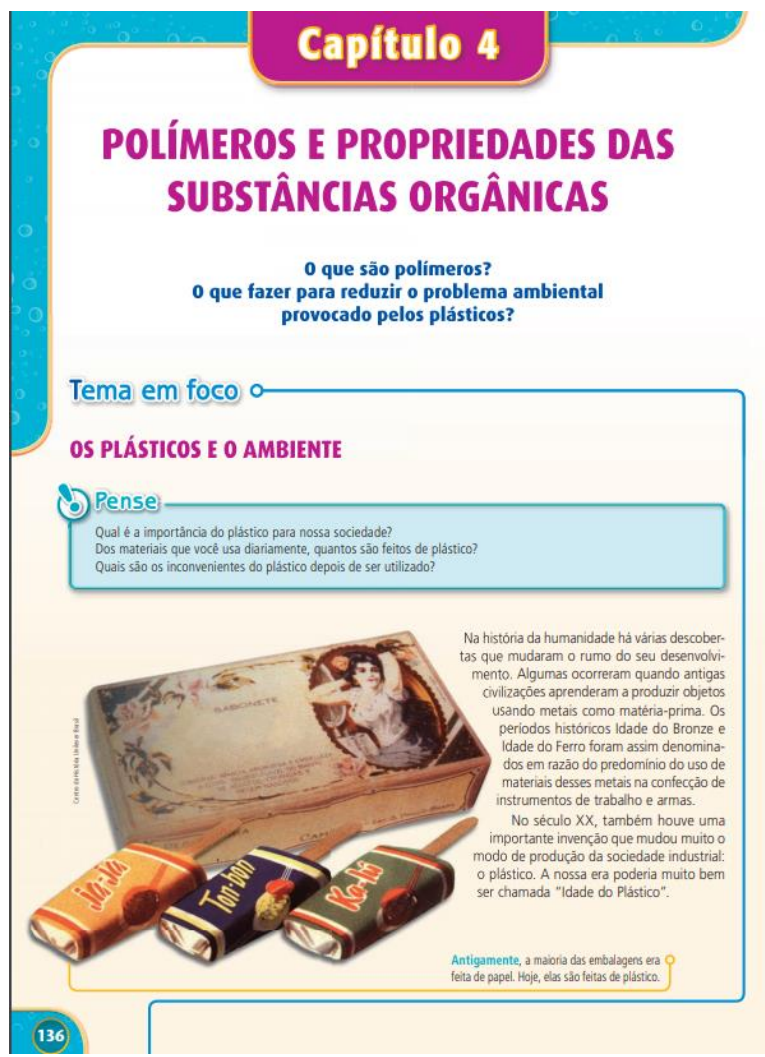

Fonte: Livro Química Cidadã (Santos e Mól, 2013) 
As autoras Pereira e Costa (2013) destacam que com o avanço das tecnologias ocorre uma rápida substituição dos produtos e com essa troca vem o resíduo eletrônico, e esse pode ser abordado de diversas maneiras na escola como pesquisa, texto, vídeos, uso de livros didáticos entre outras sempre na busca de trabalhar ao máximo a temática de lixos eletrônicos. Diante da problematização abordada, o docente realizou reuniões com a equipe diretiva para propor um projeto com a turma do $3^{\circ}$ ano do Ensino Médio e apresentar suas ideias para esclarecer o que se pretendia realizar no ambiente escolar antes de realizar a quarta etapa que consistia na criação de coletores de resíduos. Foi realizada ainda uma reunião com a bióloga do município de Rosário do Sul para obter informações sobre o sistema de coletas de resíduos do município.

Após a reunião com a bióloga, o professor regente do Componente Curricular de Química conversou com a turma para sobre a produção de um coletor de resíduos, na discussão inicial sobre consumimos e geração de resíduos os estudantes sugeriram realizar na escola um projeto com coletores de papeis, plásticos e matéria orgânica. Entretanto, após o diálogo estabelecido com a bióloga responsável optou por realizar a construção de coletores de resíduos eletrônicos, uma vez que o município não tem política de destino para reciclagem. Desta forma, sugeriu-se para a turma implantar uma coleta seletiva de eletrônicos na escola, tais como: celulares, pilhas, baterias, teclados, mouse, monitor e fone de ouvido, visto que o município possui uma parceria como uma empresa coletora de Porto Alegre que recolhe os resíduos na prefeitura.

Diante do exposto o docente instruiu a turma para realizar a confecção de coletores de lixo eletrônicos separando os estudantes em dois grupos (A e B). Como resultado da quarta etapa a figura 2 representa um dos coletores de lixo eletrônico produzido pelo grupo A da turma do $3^{\circ}$ ano do Ensino Médio. $O$ coletor foi deixado no hall do colégio com objetivo de lembrar diariamente os estudantes acerca da separação e recolhimento de eletrônicos. O grupo A confeccionou o coletor utilizando materiais como papelão, papel EVA, TNT, lápis de cor, tinta e folha branca. 
Figura 2. Coletor de lixo eletrônico, produzido pelos alunos do $3^{\circ}$ ano.

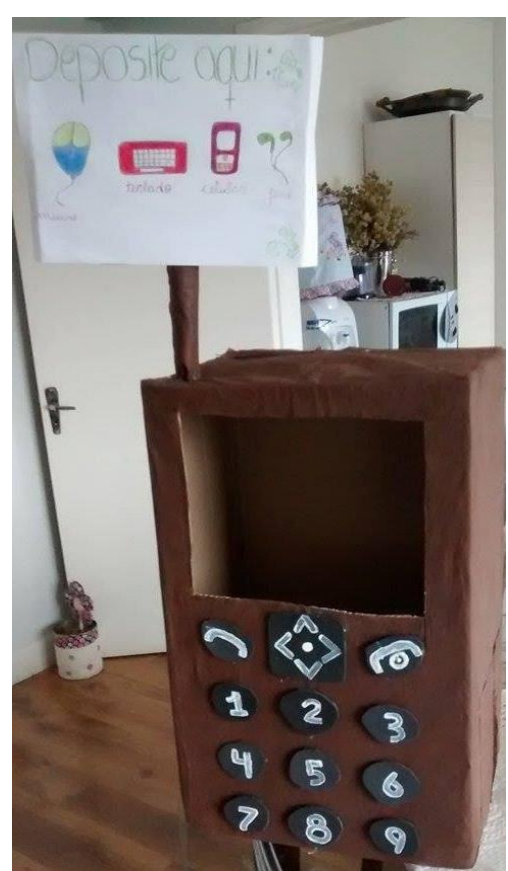

Fonte: Arquivos dos autores

Tanto o grupo A representado na figura acima como o grupo B tinham como requisito a construção de coletores para eletrônicos e esses deveriam ter indicação dos materiais que poderiam ser depositados. Pode-se observar pela própria imagem que o coletor estava destinado para recolhimento de mouse, fones de ouvidos, celulares e teclados. A campanha de recolhimento não era limitada apenas aos itens descritos na placa, mas tinha a intenção de ajudar a lembrar a comunidade escolar a trazer os materiais em desuso em casa para colocar no coletor. Pereira e Costa apontam que a escola é um ótimo canal de comunicação

\begin{abstract}
A escola pode servir de canal para a distribuição de informações úteis à preservação e conservação do meio ambiente, além de servir como base para fins educativos e ecológicos. A escola é, talvez, o local mais apropriado para este tipo de educação, pois ela pode encorajar ações, através de planos, projetos e programas de Educação Ambiental, além de facilitar a comunicação e a troca de experiências entre os alunos e os educadores ambientais (PEREIRA; COSTA, 2013, p.7).
\end{abstract}

$\mathrm{Na}$ quinta etapa os estudantes foram desafiados a confeccionar um panfleto na tentativa de sensibilizar e apresentar a temática de lixo eletrônico aos estudantes do Ensino Fundamental II. Os dois grupos que confeccionaram os coletores foram divididos novamente totalizando quatro equipes. $O$ 
professor de química conduziu os estudantes até o laboratório de informática do colégio para explicar a propostas e passar algumas informações sobre a construção dos panfletos. O trabalho iniciou-se em aula e os estudantes tiveram o prazo de duas semanas para finalizar a produção do panfleto informativo. Após a confecção dos panfletos os grupos enviaram por e-mail para o docente avaliar e sugerir suas considerações antes de realizar a impressão dos mesmos. Os panfletos foram construídos no programa power point 2010 da Microsoft office e impressos na dimensão de dois por folha de ofício no tamanho A4.

Ao todo foram confeccionados quatro panfletos que foram distribuídos do 6 ao 9ano, cada um dos grupos ficou responsável por distribuir o panfleto e explicar sobre lixo eletrônico e apresentar a proposta dos coletores. Cada turma recebeu apenas um modelo de panfleto (Figura 3) construído por um dos grupos do $3^{0}$ ano do Ensino Médio, totalizando propostas diferenciadas ao longo dos diferentes anos do Ensino Fundamental II.

Figura 3 Panfletos produzidos pela turma do $3^{\circ}$ ano do ensino.
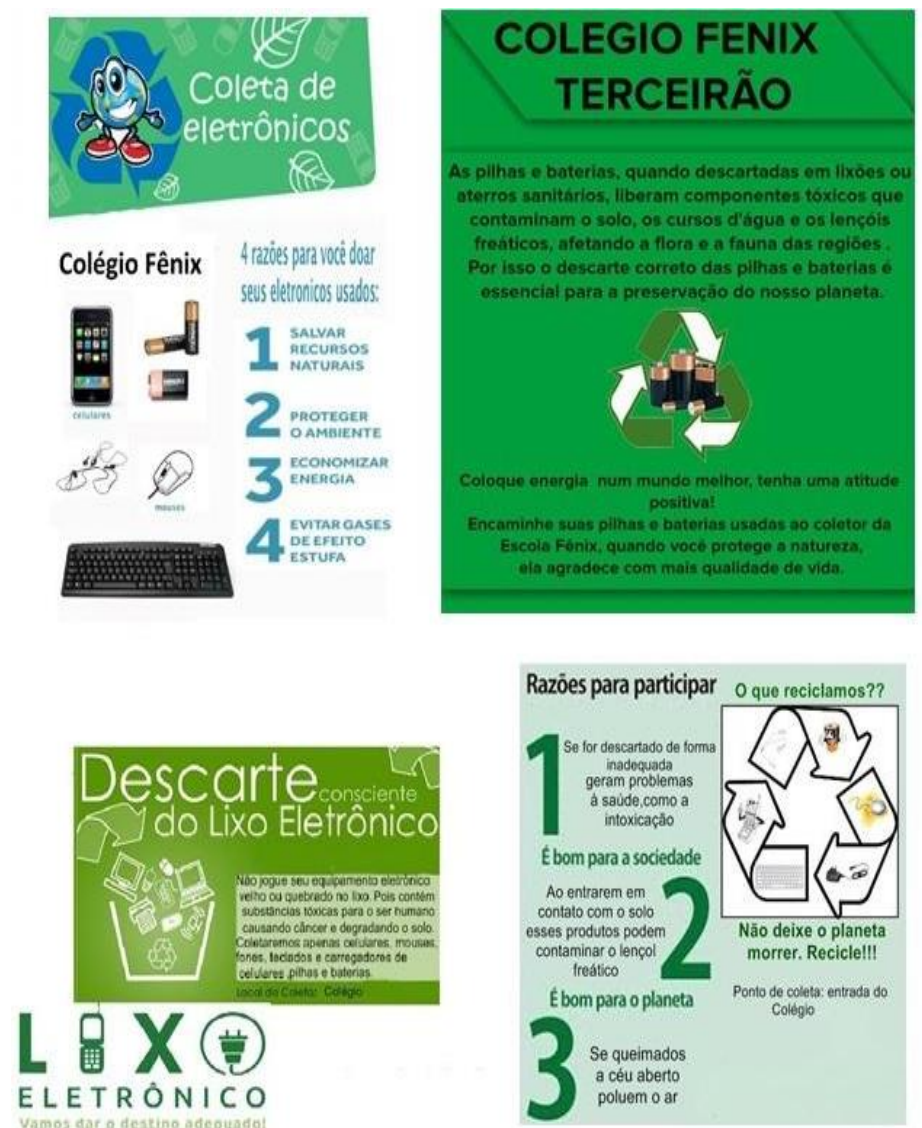

Fonte: Arquivos dos autores 
A quinta atividade da SD consistia na elaboração dos panfletos tendo como objetivo apresentar os riscos que o lixo eletrônico representava para a sociedade e ao ambiente, além de convidar a comunidade escolar para participar juntos da campanha de coleta do lixo eletrônico promovido pela turma do $3^{\circ}$ ano do Ensino Médio. Cada grupo visitou uma das quatro turmas do Ensino Fundamental II no turno da manhã para conversar com os estudantes, distribuir os folhetos e convidá-los a participar da campanha. A pesquisa realizada por Oliveira, Gomes e Afonso (2010) apontam que em torno de 600 estudantes não tinham consciência do custo ambiental e danos que os eletrônicos causavam ao ambiente, justificando-se assim a necessidade de abordar a temática de lixo eletrônico em escolas na busca de sensibilização dos discentes.

Na sexta etapa as três turmas do Ensino Médio participaram no auditório do colégio de uma palestra com a bióloga do Município de Rosário do Sul sobre o tema de resíduos sólidos (Figura 4).

Figura 4. Palestra sobre resíduos sólidos com o Ensino Médio

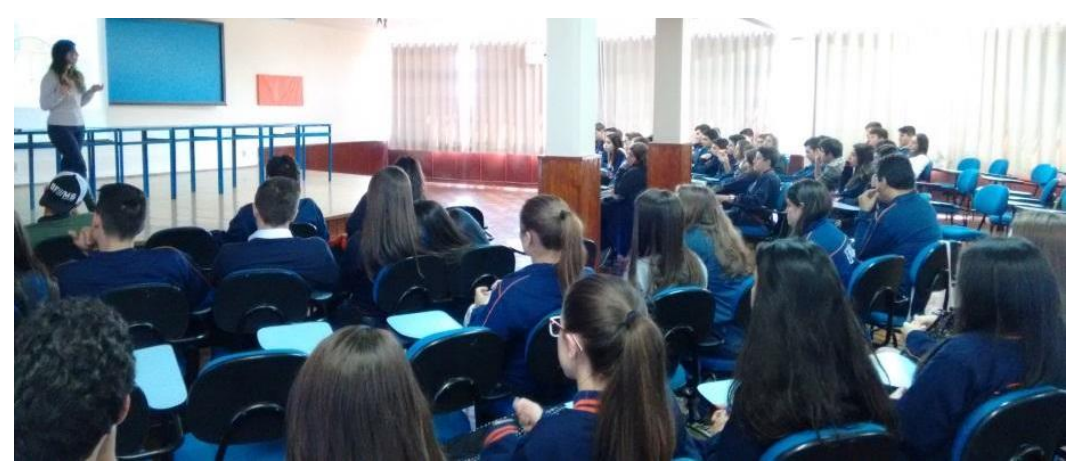

Fonte: Arquivos dos autores

A palestra permitiu tratar sobre a Política Nacional de Resíduos Sólidos (PNRS) a Lei de oo 12.305 de 2010, além de realizar reflexões e esclarecimentos sobre a produção de resíduos a nível global, regional e local. Após a exposição a palestrante abriu espaço para dúvidas e perguntas que os estudantes gostariam de realizar.

Momentos que geram reflexões nos estudantes são de substancial importância, uma vez que nesses momentos o docente pode através de temáticas ambientais iminentes tentar uma aproximação com os discentes na 
tentativa de sensibilização quanto a problemáticas ambientais. Oliveira, Gomes e Afonso (2010) enfatizam que para ter uma mudança comportamental é necessário um trabalho de Educação Ambiental voltada para consumo consciente, visto que a velocidade de troca dos eletrônicos e desenfreada e a sociedade é vítima do consumo compulsivo. Os pesquisadores supracitados afirmam que EA é essencial para mudança de atitude de crianças e jovens e esses agem como multiplicadores com as pessoas ao redor, sendo assim a escola e educadores chaves importantíssimas que auxiliam neste processo de sensibilização ambiental.

O projeto sobre resíduos eletrônicos possibilitou abordagem da química de forma contextualizada com a realidade dos estudantes e não apenas teórica e abstrata como muitas vezes é trabalhada. A SD foi desenvolvida por diferentes etapas na tentativa de possibilitar a atuação dos estudantes de forma ativa e que as atividades fossem ao longo do trajeto sensibilizando a turma em relação a geração de resíduos sejam eles eletrônicos ou não.

\section{Considerações finais}

Compreende-se que não basta somente a realização do projeto de coleta de eletrônicos, é necessária uma reflexão do caminho em que estamos percorrendo, das atitudes e o modo de consumo que alcançamos com a nossa atual visão de mundo. Deve ser trabalhado em sala de aula cada vez a uma formação de cidadania responsável e de harmonia e equilíbrio com a natureza.

A administração do município deve atender os interesses da comunidade, sendo assim uma das formas de realizá-la é por meio do desenvolvimento de um trabalho que propicie a comunicação com a comunidade. A comunicação pode ser realizada por diferentes meios como por meio do rádio, televisão, jornais e panfletagem apresentando as ações que estão sendo realizadas no município e a importância de colaborar com a coleta dos resíduos eletrônicos.

A comunidade escolar responsabilizando-se e participando do projeto atua de maneira corresponsável, estas são ações necessárias para as mudanças de atitudes para que possamos proteger a nossa sociedade e os recursos naturais como o solo, água, fauna e a flora em que vivemos e devemos conviver em harmonia, sem depositar resíduos que possam diminuir 
a qualidade do ambiente. O sujeito torna-se pouco a pouco mais comprometido com as questões ambientais, no momento em que reflete e compreende que está inserido e que suas atitudes refletem na sua própria qualidade de vida direta ou indiretamente.

A atividade realizada pelos estudantes permitiu trabalhar com tema de relevância para a comunidade local, contextualizar o Ensino de Química e promover ações de cidadania nos estudantes tais como retomar as responsabilidades com a sociedade e o meio ambiente, além de desenvolver atitudes colaborativas para melhorar a qualidade de vida da comunidade.

A produção dos panfletos buscou desenvolver a capacidade de manuseio das ferramentas digitais, da busca por informações e na elaboração da linguagem que alcançassem os objetivos de comunicação com a comunidade escolar. As autonomias dos estudantes nas atividades relacionadas ao lixo eletrônico demonstram uma busca pela sensibilização a comunidade escolar, como um convite para que participassem juntos da coleta do lixo eletrônico. Essas ações permitiram sensibilização dos estudantes sobre o consumismo, questão de obsolescência programada dos eletrônicos com um pensamento voltado a reduzir, reciclar e reutilizar de forma a preservar e cuidar a sociedade e o meio ambiente.

\section{Referências}

ABREU, Daniela Gonçalves de; CAMPOS, Maria Lúcia A. M.; AGUILAR, M. B. $R$. Educação ambiental nas escolas da região de ribeirão preto: concepções orientadoras da prática docente e reflexões sobre a formação inicial de professores de química. Química Nova. vol.31, n.3, p.688-693, 2008. Disponível em:

http://www.scielo.br/scielo.php?pid=S0100-

40422008000300037\&script=sci_abstract\&tlng=es. Acesso em: 22 mar. 2018.

BAIRD, Colin; CANN, Michael. Química Ambiental. Tradução: Marco Tadeu Grassi et al. 4.ed. Porto Alegre: Bookman, 2011.

BARBOSA, Vanessa. Brasil gerou 1,5 milhão de toneladas de lixo eletrônico em 2016. Revista Exame. 2018. Disponível em:<https://exame.abril.com.br/brasil/brasil-gerou-15-milhao-de-toneladas-delixo-eletronico-em-2016/>. Acesso em: 10 ago. 2018.

BEGNAME, Thamirys; SILVA, Kelly da.; TOSTES, Renata Barreto; RESENDE, Cristiana Marcelo; RESENDE, Luciana Marcelo. Educação ambiental: uma prática interdisciplinar entre universidade e escola. Educação Ambiental em 
Ação, 2015. Disponível em:

http://www.revistaea.org/artigo.php?idartigo=2110. Acesso em: 12 abri. 2018.

BRASIL, LDB. Lei 9394/96 - Lei de Diretrizes e Bases da Educação Nacional. Disponível em < www.planalto.gov.br >. Acesso em: 25 Jun. 2018.

BRASIL. Lei oㅜ 12.305, de 2 de agosto de 2010. Institui a Política Nacional de Resíduos Sólidos; altera a Lei no 9.605, de 12 de fevereiro de 1998; e dá outras providências. Disponível em: http://www2.mma.gov.br/port/conama/legiabre.cfm?codlegi=636. Acesso em: 15 ago. 2018.

BRASIL. Política Nacional de Educação Ambiental, Lei 9795. Diário Oficial da República Federativa do Brasil, Brasília, DF, 27 abr. 1999. Disponível em:< http://www.planalto.gov.br/ccivil_03/LEIS/19795.htm>. Acesso em: 15 mar. 2018.

BRASIL, Programa de Educação Ambiental. Educação Ambiental: Por um Brasil Sustentável. 4ed. Brasília: 2014. Disponível em: http://www.mma.gov.br/images/arquivo/80221/pronea 4edicao web-1.pdf. Acesso em: 8 set. 2017.

CARVALHO, Isabel Cristina de Moura. Educação ambiental: a formação do sujeito ecológico. Editora Cortez: São Paulo, 2004.

CUBA, Marcos Antonio. Educação Ambiental nas escolas. ECCOM. v.1, n.2, p.23-31, 2010. Disponível em: http://publicacoes.fatea.br/index.php/eccom/article/viewFile/403/259. Acesso em: 15 ago. 2018.

LIMA, Verônica Ferreira; MERÇON, Fábio. Metais Pesados no Ensino de Química. Química Nova na Escola. vol.33, n.4, nov., 2011. Disponível em: http://anesc.sbq.org.br/online/qnesc33 4/199-CCD-7510.pdf. Acesso em: 17 ago. 2018.

OLIVEIRA, Rafael da Silva; GOMES, Elisa Silva; AFONSO, Júlio Carlos. O Lixo eletroeletrônico: Uma abordagem para o ensino fundamental e médio. Química Nova na Escola. v. 32, n. 4, p. 240-248, 2010. Disponível em: http://qnesc.sbq.org.br/online/qnesc32 4/06-RSA10109.pdf. Acesso em: 20 ago. 2018.

PEREIRA, Cláudia Regina da Fonseca; COSTA, Vânia Sueli da. Educação ambiental na escola: subsídios para descarte/ reutilização de resíduos eletrônicos. In: IV CONGRESSO BRASILEIRO DE GESTÃO AMBIENTAL, 1., IBEAS Salvador: UFBA. Salvador, 2013. Disponível em: http://www.ibeas.org.br/congresso/Trabalhos2013/lll-028.pdf. Acesso em: 4 jul. 2018.

PEREIRA, Luciano de Almeida; NICÁCIO, Marco Antônio; BOTELHO, Maria Luiza Silva Tupy; SILVA. Gabriela Fioravante da. Descarte de equipamentos eletrônicos: uma abordagem CTS no ensino profissionalizante de Química. XVI 
Encontro Nacional de Ensino de Química (XVI ENEQ) e X Encontro de Educação Química da Bahia (X EDUQUI). Salvador, BA, 2012. Disponível em:

https://portalseer.ufba.br/index.php/anaiseneq2012/article/viewFile/8034/5747. Acesso: 13 mai. 2018.

SANTOS, W. MÓL, G.: Química Cidadã. v.3, p.136-141, Nova Geração, São Paulo, 2013.

SILVA, Claudionor Oliveira; OLIVEIRA, Fabrício Silva; TORRES, Moisés Silva. Coleta seletiva e reciclagem como cultura ambiental no contexto escolar. GEOSABERES. v.5, n.9, p.13-25, 2014. Disponível em: http://www.periodicos.ufc.br/geosaberes/article/view/1046. Acesso 27 mar. 2018.

TRAVASSOS, E. G. A prática da educação ambiental nas escolas. $2^{\circ}$ ed. Editora Mediação: Porto Alegre, 2006.

ZABALA, A. A prática Educativa: Como Ensinar. Tradução Ernani F. da F. Rosa. Porto Alegre: Artmed, 1998.

ZORZAN, Marilaine; BERTAN, Fernanda Aparecida Brocco. Abordagem da problemática do lixo eletrônico em uma Escola Estadual de Dois Vizinhos - PR: Pequenas Atitudes que podem fazer grande diferença. XIII Congresso Nacional de Educação (EDUCERE). Paraná, 2017. Disponível em: http://educere.bruc.com.br/arquivo/pdf2017/23780 11962.pdf. Acesso: 10 jun. 2018.

WUILLDA, Aline C. J. S.; OLIVEIRA, Camila. A.; VICENTE, Jéssica S.; GUERRA, Antonio. C. O.; SILVA, Joaquim. F. M. Educação ambiental no Ensino de Química: Reciclagem de caixas Tetra Pak® na construção de uma tabela periódica interativa. Química Nova na Escola. vol. 39, n.3, p.268-276. ago., 2017. Disponível em: http://qnesc.sbq.org.br/online/qnesc39 3/08-RSA120-15.pdf. Acesso: 19 jul. 2018. 